\title{
Recovery of Uranium by Se-Derivatives of Amidoximes and Composites Based on Them
}

\author{
Eduard Tokar ${ }^{1,2}\left(\mathbb{D}\right.$, Konstantin Maslov ${ }^{2}$, Ivan Tananaev ${ }^{2}$ and Andrei Egorin ${ }^{1, *(D)}$ \\ 1 Institute of Chemistry, Far Eastern Branch of Russian Academy of Sciences, 690022 Vladivostok, Russia; \\ users@local.ich.dvo.ru \\ 2 School of Life Sciences, Far Eastern Federal University, 690090 Vladivostok, Russia; \\ maslov.kv@dvfu.ru (K.M.); geokhi@mail.ru (I.T.) \\ * Correspondence: andrey.egorin@gmail.com
}

Citation: Tokar, E.; Maslov, K.; Tananaev, I.; Egorin, A. Recovery of Uranium by Se-Derivatives of Amidoximes and Composites Based on Them. Materials 2021, 14, 5511. https://doi.org/10.3390/ma14195511

Academic Editor: Dorota Kołodyńska

Received: 23 July 2021

Accepted: 16 September 2021

Published: 23 September 2021

Publisher's Note: MDPI stays neutral with regard to jurisdictional claims in published maps and institutional affiliations.

Copyright: (C) 2021 by the authors Licensee MDPI, Basel, Switzerland. This article is an open access article distributed under the terms and conditions of the Creative Commons Attribution (CC BY) license (https:// creativecommons.org/licenses/by/ $4.0 /)$.

\begin{abstract}
An Se-derivative of amidoxime was synthesized for the first time as a result of the reaction of oxidative polycondensation of $\mathrm{N}^{\prime}$-hydroxy-1,2,5-oxadiazole-3-carboximidamide with $\mathrm{SeO}_{2}$ : its elementary units are linked to each other due to the formation of strong diselenide bridges. The element composition of the material was established, and the structure of the elementary unit was suggested. The sorption-selective properties were evaluated, and it was found that the adsorbent can be used for the selective recovery of $U$ (VI) from liquid media with a $\mathrm{pH}$ of $6-9$. The effect of some anions and cations on the efficiency of recovery of $U$ (VI) was estimated. Composite materials were fabricated, in which silica gel with a content of 35, 50, and $65 \mathrm{wt}$. \% was used as a matrix to be applied in sorption columns. The maximum values of adsorption of $U$ (VI) calculated using the Langmuir equation were $620-760 \mathrm{mg} \mathrm{g}^{-1}$ and $370 \mathrm{mg} \mathrm{g}^{-1}$ for the composite and non-composite adsorbents, respectively. The increase in the kinetic parameters of adsorption in comparison with those of the non-porous material was revealed, along with the increase in the specific surface area of the composite adsorbents. In particular, the maximum sorption capacity and the rate of absorption of uranium from the solution increased two-fold.
\end{abstract}

Keywords: uranium; amidoximes; sorption; 1,2,5-oxadiazoles; selenium

\section{Introduction}

The growing demand for uranium ore due to its widespread use in the nuclear industry is accompanied by the accumulation of solid and liquid radioactive waste containing uranium and its daughter decay products. The process of continuous release of uranium and its decay products to the biosphere occurs from rocks and parent rocks due to natural factors. This process is intensified during the mining and subsequent processing of uranium ore at nuclear industry facilities, thus creating risks of contamination of natural waters used in agriculture, as well as sources of drinking water [1]. Considering the highly toxic and radiotoxic hazards of uranium isotopes, characterized by a wide range of water-soluble forms in the biosphere, there is an urgent task to find methods for its selective recovery and concentration from natural and technological waters, including treating it as a valuable raw material.

A number of methods were developed over the past few decades for the recovery of uranium from aqueous solutions: extraction [2], membrane filtration [3], photocatalysis [4], chemical precipitation [5], electrocoagulation [6], adsorption [7], and others. However, most traditional methods have their disadvantages. In particular, despite the high efficiency of uranium extraction by membrane filtration, the main disadvantages of this method include the high energy costs required to restore the membranes and maintain high pressure [4]. The chemical deposition method is quite simple and economical, but it is often ineffective for reducing the concentration of uranium below the legally permissible levels and tends to form secondary wastes [5]. In addition, under conditions of working with high-salinity 
solutions, the production of a pure precipitate of uranium salts is complicated by the precipitation of salts of related metals, which requires an additional separation stage.

Among all the known methods, the most preferred is selective adsorption, which is free from most of the above disadvantages. Various natural and synthetic materials can be used as adsorbents. As examples of natural adsorbents, one can single out various types of aluminosilicates, such as kaolinite [8], montmorillonite [9], etc. The advantages of natural aluminosilicates include low cost, mechanical strength, and absence of negative impact on the environment so that these materials are often used to create migration barriers. However, low selectivity limits the practical use of aluminosilicates for the recovery of uranium isotopes.

The class of synthetic materials includes a large number of different adsorbents, which can be divided into inorganic and organic ones, and composites based on them. However, most of the known adsorbents have a number of limitations of application, such as a narrow range of the working $\mathrm{pH}$ of the solution [10], low kinetic parameters of radionuclide adsorption [11], and the use under conditions of low mineralization [11] due to the strong influence of competing ions.

Here, oxides and hydroxides of the following metals can be used as inorganic materials for the recovery of uranium from liquid media: Mn [12], Fe [13], Ti [14,15], Al [16], etc. They can be used for the recovery of uranium from various liquid media, including seawater in a wide $\mathrm{pH}$ range. The disadvantages of these sorbents include low adsorption capacity, as well as partial destruction, which leads to the desorption of uranium [17]. The authors of $[10,18]$ suggested using titanosilicates, amorphous spherical granular phosphates, and titanium phosphatosilicates as adsorbents for the extraction of uranium isotopes. The disadvantage of the latter materials consists in their use for the recovery of just cationic forms of radionuclides, i.e., from aqueous media with $\mathrm{pH}$ less than 5.5.

Chitosan is a well-known adsorbent, which is used to recover uranium from mining wastewaters generated during the processing of uranium-containing ores. The sorption properties of chitosan towards uranium are determined by the presence of glucosamine and acetyl-glucosamine functional parts with hydroxyl and amino groups [19]. One of the representatives of this class of sorbent is the fibrous chitin-melanin glucan complex Mikoton obtained from higher fungi [20]. A number of studies [20,21] demonstrated the prospects of using various modifications of this sorbent for the selective recovery of a number of radionuclides such as $\mathrm{Cs}, \mathrm{Sr}, \mathrm{Am}, \mathrm{Pu}$, and $\mathrm{U}$. A special feature of this sorbent consists in its fine-fiber structure characterized with high mechanical strength, thus providing an exceptionally developed surface, which allows it to be used under harsh sorption conditions. A large number of functional groups and the ionic permeability of the material contribute to a greater sorption capacity. However, despite the unique physical and chemical properties of the material, high sorption-selective characteristics of sorbents are attained at a $\mathrm{pH}$ of less than 5 , which significantly limits the scope of their application.

Among organic adsorbents, materials with chelating functional groups, such as amino, sulfhydryl, carboxyl, amidoxime, and imidiacetate, are of the greatest interest due to their significantly high adsorption capacity for binding uranium, which is the result of ion exchange and complexation reactions [22-24].

Sorption materials that have an amphoteric ligand amidoxime with an acidic oxime and basic amino groups in their structure are of particular interest. This ligand allows the formation of stable chelates with a wide range of heavy metals, including $\mathrm{Pb}^{2+}, \mathrm{Cu}^{2+}, \mathrm{Cd}^{2+}$, $\mathrm{Co}^{2+}$, and $\mathrm{Ni}^{2+}$, as well as a five-membered chelate with $\mathrm{U}(\mathrm{VI})$, by providing lone-pair oxygen electrons at the oxime and amino groups to a positively charged metal [25].

In early studies of the use of amidoximes for metal binding in aqueous solutions, it was suggested that this class of materials was the most effective for recovering uranium from liquid media [26]. The authors of [27] showed the binding of uranyl ions in the uranylacetamidoxime complex with stability constants greater than $1 \times 10^{10}$, which indicated high selectivity of the materials. In order to increase the sorption capacity, composite sorbents were synthesized by amidoximation of the following materials: polyethylene [28,29], 
carbon tubes [30], chitosan [31], and cellulose [32]. However, despite high selectivity towards uranium and high sorption capacity, their use in real conditions is limited by low hydro-mechanical strength [30] and solubility in alkaline media [31]. The use of polyurethane foam to increase the specific surface area leads to partial or complete blockage of the pores in the process of chemical modification [28,29]. Besides, the multi-step synthetic modification leads to the decrease in the degree of inoculation of amidoxime and spatial separation of chelate groups in the sorbent, which adversely affects the ability to bind uranyl ions and decreases the affinity. The materials comprising ordered three-dimensional coordination polymers consisting of metal cations $(\mathrm{Al}, \mathrm{Zn})$ and amidoxime radicals [33] are promising - they exhibit high sorption capacity.

To sum up, sorption materials based on amidoxime compounds are actively studied from the practical point of view, where they have proven to be highly effective for recovering uranyl ions from anthropogenic and natural liquid media with high contents of carbonates and sulfates, as well as seawater.

Despite significant advances in the production of polymer organic materials based on amidoximes and oximes, methods of production and properties of organic sorbents with an inorganic component of the Se type were not earlier published. In view of this, the objective of the present work was to synthesize new derivatives of 4-aminofufazane-3carboxamidoxime, both in the pure form and as mechanically strong composites based on silica gel, through the introduction of heteroelements of high coordination capacity, which would facilitate the formation of polymer materials characterized with developed structure and high content of ion-exchange groups (amino and hydroxyl groups) and distinguished by an increased selectivity to uranium.

\section{Materials and Methods}

Selenium dioxide, acetic acid, ethanol, and methylene chloride of the especially pure grade were used to prepare the sorption material, as well as silica gel with a particle size of 35-70 mesh. In order to prepare working solutions simulators, metal salts of the chemically pure grade were used without additional purification - they were purchased from Nevareaktiv LLC (Saint-Petersburg, Russia). The radionuclide U-235 in the form of $\mathrm{UO}_{2}\left(\mathrm{NO}_{3}\right)_{2}$ of the especially pure grade was used as a sorption element.

\subsection{Preparation of Materials}

The 4-aminofurazane-3-carboxamidoxime (compound 1) was preliminarily synthesized by the following method [34]. An amount of $7.6 \mathrm{~g}$ of sodium nitrite (110 mmol) was gradually added to $140 \mathrm{~mL}$ of a solution of malononitrile $(100 \mathrm{mmol})$ under intensive stirring at $20{ }^{\circ} \mathrm{C}$, and then the mixture was cooled down to $5{ }^{\circ} \mathrm{C}$. Thereafter, for $15-20 \mathrm{~min}$, $3.8 \mathrm{~mL}$ of concentrated $\mathrm{H}_{3} \mathrm{PO}_{4}$ solution was added to it drop by drop under intensive stirring; the mixture was again stirred for $1.5 \mathrm{~h}$ and cooled down to $15-20{ }^{\circ} \mathrm{C}$. Finally, $21 \mathrm{~g}$ of hydroxylamine hydrochloride $(0.3 \mathrm{~mol})$ was added to the mixture, and the stirring continued until the latter was completely dissolved. Thereafter, the mixture was alkalized to $\mathrm{pH} 10$ using a solution of $\mathrm{KOH}(0.45 \mathrm{~mol})$ and boiled for $2 \mathrm{~h}$. The resulting solution was slowly cooled down to room temperature and acidified to $\mathrm{pH} 7$ using a $30 \% \mathrm{H}_{3} \mathrm{PO}_{4}$ solution. The resulting mixture was held at $0-5^{\circ} \mathrm{C}$ for $12 \mathrm{~h}$ for crystallization, and the final compound was filtered and washing with cold water. The yield of compound $\mathbf{1}$ was $75-85 \%$. Prior to use, compound 1 was recrystallized from an aqueous solution in the presence of activated carbon.

\subsection{Synthesis of the Se-Derivative $N^{\prime}$-hydroxy-1,2,5-oxadiazole-3-carboximidamide}

A mixture of $1.43 \mathrm{~g}$ (10 mmol) 4-aminofurazane-3-carboxamidoxime 1 and Se(IV) oxide with a weight of $1.11 \mathrm{~g}(10 \mathrm{mmol})$ was boiled in acetic acid $(30 \mathrm{~mL})$ with a reverse refrigerator for 80-100 min under intensive stirring, a dark purple precipitate was formed as a result. At the end of the reaction, the mixture was cooled down to room temperature, and then the precipitate was separated from the mother liquor by a blue ribbon filter (JSC 
"ECOS-1", Moscow, Russia). The precipitate was then washed sequentially with cold distilled water (three times), ethanol (once), and methylene chloride (once) to remove the unreacted components of the initial mixture. The resulting product was dried to a constant weight in a vacuum desiccator at 5-10 mm Hg above $\mathrm{P}_{2} \mathrm{O}_{5}$ at a temperature of $20-25{ }^{\circ} \mathrm{C}$ for $24 \mathrm{~h}$. The final material, denominated as Se-init had a yield of $80-90 \%$ and comprised dark purple granules of an irregular shape with a grain size of 0.05-0.2 $\mathrm{mm}$ [35].

\subsection{Synthesis of Composite Sorbents}

In order to prepare composite samples, silica gel was added to a mixture of $1.43 \mathrm{~g}$ (10 mmol) of 4-aminofurazane-3-carboxamidoxime, $1.11 \mathrm{~g} \mathrm{(10} \mathrm{mmol)} \mathrm{of} \mathrm{selenium} \mathrm{dioxide,}$ and $30 \mathrm{~mL}$ of acetic acid during boiling. Boiling of the mixture lasted 80-100 min under intensive stirring. After completely falling out of the dark purple precipitate, the boiling was stopped, and the mixture was gradually cooled to room temperature and filtered. The resulting material was washed with cold water (three times), ethanol (twice), and methylene chloride to remove unreacted organic compounds. The final product was dried to a constant weight in a vacuum oven at $50{ }^{\circ} \mathrm{C}$. The prepared materials comprised dark purple powders with a grain size of $0.05-0.2 \mathrm{~mm}$. Three types of composite materials were fabricated; they were denominated as Se-35, Se-50, and Se-65, with a silica gel content of 35, 50 , and $65 w t . \%$, respectively.

\subsection{Study of Sorption Characteristics under Static Conditions}

In the sorption experiments, initially, the U(VI) salt (nitrate) was used. However, to simplify the description, hereinafter, U(VI) and its possible forms of existence will be marked as just uranium.

The sorption properties of the fabricated materials were investigated using solutions of $\mathrm{pH}$ of $2-10$ containing uranium with the ratio $\mathrm{V} / \mathrm{m}=1000 \mathrm{~mL} \mathrm{~g}^{-1}$ ( $V$ is the volume of the model solution, $m$ is the weight of the sorbent). The phase contact time was $48 \mathrm{~h}$ under continuous stirring on an orbital shaker with an amplitude of $10 \mathrm{~mm}$ and a rotation speed of $150 \mathrm{rpm}$. Prior to the start of the uranium recovery experiment, the sorbent samples were held for $24 \mathrm{~h}$ in the model solutions that did not contain uranium.

At the end of the experiment, the model solution was separated from the sorbent by a blue ribbon filter, and the residual uranium ${ }^{+}$content was analyzed by the spectrophotometric method using Arsenazo III at a wavelength of $656 \mathrm{~nm} \mathrm{[36].} \mathrm{The} \mathrm{results} \mathrm{obtained} \mathrm{were} \mathrm{used}$ to further calculate the extraction efficiency $(\mathrm{S} \%)$ and the uranium distribution coefficients $\left(K_{d}, \mathrm{~mL} \mathrm{~g}^{-1}\right)$ :

The extraction efficiency was calculated according to Equation (1):

$$
S=\left(1-\left(\frac{C_{e}}{C_{i}}\right)\right) \times 100
$$

The value of the uranium distribution coefficient $\left(\mathrm{mL} \mathrm{g}^{-1}\right)$ was calculated using Equation (2):

$$
K_{d}=\frac{C_{i}-C_{e}}{C_{i}} \times \frac{V}{m}
$$

where $C_{i}$ is the initial concentration of uranium in the solution $\left(\mathrm{mg} \mathrm{L}^{-1}\right), C_{e}$ is the equilibrium residual concentration of uranium in the solution $\left(\mathrm{mg} \mathrm{L}^{-1}\right), V$ is the volume of the solution $(\mathrm{mL})$, and $m$ is the weight of the sorbent sample $(\mathrm{g})$. Additionally, at the end of the experiment, the equilibrium $\mathrm{pH}$ of the solution was measured, followed by the determination of the zero charge point ( $\mathrm{pHpzc}$ ) by a graphical method.

The effect of the presence of cations and anions in the solution on the static exchange capacity was evaluated in the presence of solutions of metal chlorides $\left(\mathrm{K}^{+}, \mathrm{Na}^{+}, \mathrm{Mg}^{2+}, \mathrm{Ca}^{2+}\right.$, $\mathrm{Co}^{2+}$, and $\left.\mathrm{Ni}^{2+}\right)$ or sodium salts $\left(\mathrm{HCO}_{3}{ }^{-}, \mathrm{NO}_{3}{ }^{-}, \mathrm{Cl}^{-}, \mathrm{SO}_{4}{ }^{2-}\right.$, and $\left.\mathrm{PO}_{4}{ }^{3-}\right)$, respectively. Solutions with the following concentration of the corresponding cations or anions were 
used: $0.001 ; 0.001 ; 0.01 ; 0.1 \mathrm{~mol} \mathrm{~L}^{-1}$. The static exchange capacity (SEC, mg/g) was calculated according to the following formula:

$$
S E C=\frac{\left(C_{i}-C_{e}\right) \times V}{m}
$$

where $V$ is the volume of the solution (L).

The nature of the adsorption process was estimated from the uranium adsorption isotherms, which were obtained by contacting a series of samples of a given weight with the model solutions of $\mathrm{pH} 6$ and 8 containing a certain amount of uranium ${ }^{+}$. The standard Langmuir Equation (4) was used to describe the sorption isotherm:

$$
\Gamma=G_{\max } \times \frac{K_{l} \times C_{e}}{1+K_{l} \times C_{e}}
$$

where $G_{\max }$ is the maximum sorption value $\left(\mathrm{mg} \mathrm{g}^{-1}\right), K_{l}$ are the constants of the adsorption equilibrium characterizing the energy of the adsorbent-adsorbate bond $\left(\mathrm{L} \mathrm{g}^{-1}\right)$.

The experimental data were approximated by means of the specified equations using the SciDAVis software (version 1.23, scidavis.sourceforge.net, accessed on 15 September 2021).

The kinetic characteristics of the sorption process were evaluated using a model solution with pH 6 containing $0.1 \mathrm{~mol} \mathrm{~L}^{-1}$ of $\mathrm{NaNO}_{3}$ and $30 \mathrm{~mol} \mathrm{~L}^{-1}$ of uranium. The adsorbents were brought into contact with the model solution, $\mathrm{V} / \mathrm{m}=200 \mathrm{~mL} \mathrm{~g}^{-1}$, and, after a certain period, aliquots of the solution were taken, and the residual content of uranyl ions in the solution was determined.

The obtained kinetic curves in $\mathrm{S}_{(\mathrm{t})}$ - $\mathrm{t}$ coordinates were processed by the pseudo-firstorder (Equation (5)) and pseudo-second-order (Equation (6)) kinetic equations.

$$
\begin{gathered}
A_{t}=A_{e} \times\left(1-\exp ^{-k_{1} \times t}\right) \\
A_{t}=\frac{k_{2} \times A_{e}^{2} \times t}{1+k_{2} \times A_{e} \times t}
\end{gathered}
$$

where $A_{t}$ is the amount of adsorbed uranium at time $t\left(\mathrm{mmol} \mathrm{g}^{-1}\right), A_{e}$ is the equilibrium uranium adsorption $\left(\mathrm{mmol} \mathrm{g}^{-1}\right), t$ - time $(\mathrm{min})$, and $k_{1}$ and $k_{2}$ are the pseudo-first-order and pseudo-second-order constants, respectively.

The kinetic parameters of the adsorption process in solutions with $\mathrm{pH} 6$ and 8 were comparable; therefore, this work presents the results obtained using solutions with $\mathrm{pH} 6$.

The assessment of the hydro-mechanical strength (HMS) of the prepared sorbents was carried out as follows: a suspension of the sorbent with a weight of $1 \mathrm{~g}$ and grain size of 0.1-0.2 $\mathrm{mm}$ was mixed with $50 \mathrm{~mL}$ of distilled water for $24 \mathrm{~h}$. Thereafter, the sorbent was separated from the solution, dried to a constant weight at $105^{\circ} \mathrm{C}$, sieved again, and weighed on an analytical balance with an accuracy of $0.001 \mathrm{~g}$. The degree of destruction of the sorbent sample with a grain size of $0.1-0.2 \mathrm{~mm}$ was estimated by the ratio of the weight remaining after the mixing to the initial weight of the sample.

$$
H M S=\frac{m_{0}-m_{1}}{m_{1}} \times 100 \%
$$

where $m_{0}$ is the initial weight of the sorbent with a grain size of $0.1-0.2 \mathrm{~mm}, m_{1}$ is the weight of the sorbent that retained the grain size of $0.1-0.2 \mathrm{~mm}$ after mixing and sieving.

\subsection{Equipment}

The infrared spectra (IRS) of the samples were recorded using a Spectrum $1000 \mathrm{spec}-$ trometer (Perkin Elmer, Waltham, MA, USA) in KBr tablets. X-ray diffraction patterns were recorded using an Advance D8 (Bruker, Billerica, MA, USA) device, with $\mathrm{CuK}_{\alpha}$-radiation in the angle range of $2^{\circ}<2 \theta<90^{\circ}$ in the point-by-point scanning mode. The maximum 
deviation of the position of the reflexes, as determined through NIST SRM 1976, was less than $0.01^{\circ} 2 \theta$.

Nuclear magnetic resonance $\left({ }^{13} \mathrm{C}\right.$ NMR $)$ spectra of the polymers in the solid phase were recorded using a Bruker Advance AV-300 device (Billerica, MA, USA) with a proton resonance frequency of $300 \mathrm{MHz}$. The method of magic-angle spinning (MAS) was used to record the spectra. Tetramethylsilane was used as a standard for carbon nuclei, whereas the chemical shift (CS) zero was set in a separate experiment. The error in determining the CS did not exceed 1-2 ppm, depending on the resolution of the peak. The spectra were recorded at a temperature of $300 \mathrm{~K}$.

The X-ray photoelectron spectroscopy (XPS) spectra were obtained using an ultrahigh vacuum photoelectron spectrometer manufactured by Specs (Berlin, Germany) with a hemispherical electrostatic energy analyzer PHOIBOS (Specs, Berlin, Germany). An X-ray tube with a magnesium anode (MgKa-1253.6 eV, Specs, Berlin, Germany) was used as the radiation source. The pressure in the chamber during the measurement was $5 \times 10^{-7} \mathrm{mbar}$. The energy scale was calibrated according to the carbon level C 1s, the energy of which was assumed to be $285.0 \mathrm{eV}$. The transmission energy of the analyzer was $50 \mathrm{eV}$; the step at scanning the survey spectra was $1.0 \mathrm{eV}$, while for the detailed spectra, it was equal to $0.1 \mathrm{eV}$. At the sample preparation stage, the investigated materials were pressed onto a $1 \mathrm{~cm} \times 1 \mathrm{~cm}$ sticky conductive tape.

The high-resolution scanning electron microscopy study was performed using a HITACHI TM 3000 device (Hitachi, Tokyo, Japan) at accelerating voltages of 5-15 kV and a beam current of $\mathrm{I} \approx 100 \mathrm{pA}$. The device was equipped with an accessory for energy dispersion analysis (EDA) by Bruker (Berlin, Germany).

The specific surface area and the pore size of the material were determined by the method of low-temperature nitrogen adsorption using an Autosorb IQ device by Quantachrome Instruments (Boynton Beach, FL, USA). The calculation was performed according to the BET method (the theory of Brunauer-Emmett-Teller).

The element content in the model solution was evaluated by the atomic absorption flame spectroscopy using a Thermo Solar AA M6 device (Thermo Electron Corporation, Waltham, MA, USA). The surface morphology was studied by scanning electron microscopy (SEM) using a Carl Zeiss CrossBeam 1540-XB instrument (ZEISS Microscopy, Munich, Germany).

The content of uranyl ions in the solution was determined by the spectrophotometry method using a Shimadzu UV-1800 spectrophotometer (Kyoto, Japan).

\section{Results and Discussion}

\subsection{Physiochemical Properties}

According to the objective of the present work, the materials based on amidoxime functional groups, in particular, the Se-derivative of N'-hydroxy-1,2,5-oxadiazole-3-carboximidamide (Se-init), were studied as highly effective sorbents for uranium recovery. The choice of Se was determined by the mild selective oxidizing properties of $\mathrm{SeO}_{2}$ towards $\mathrm{N}^{\prime}$-hydroxy-1,2,5oxadiazole-3-carboximidamide. The method of preparation is based on the reaction of oxidative polycondensation of $\mathrm{N}^{\prime}$-hydroxy-1,2,5-oxadiazole-3-carboximidamide with $\mathrm{SeO}_{2}$ in the presence of polar organic solvents followed by the formation of a polymer structure, whose elementary units are linked to each other due to the formation of strong diselenide bridges. This original method offers a very simple implementation by a single-stage reaction, as well as the use of an organic radical with a large number of reactive groups (hydroxyl and oxime) that remain in the final product. A number of physical-chemical methods were used to determine the molecular structure of the resulting compound. In particular, Figure 1 shows the IR spectrum of Se-init. 


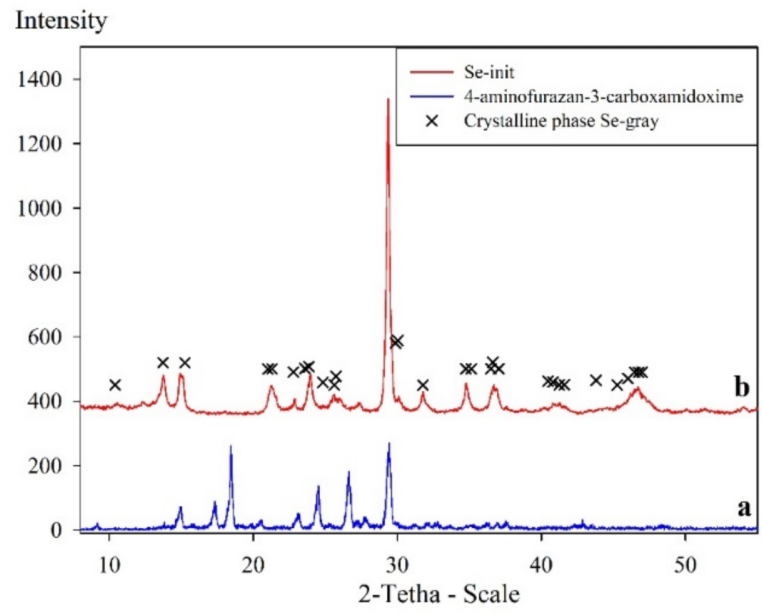

Figure 1. IR spectrum: (a) 4-aminofurazane-3-carboxamidoxime; (b) Se-init.

The bands observed in the spectrum indicate that the initial compounds are built into the general structure and preserve functional radicals. An intense absorption band is observed at $3454 \mathrm{~cm}^{-1}$, which corresponds to the $\mathrm{O}-\mathrm{H}$ vibrations at the oxime group. The absorption band at $3311 \mathrm{~cm}^{-1}$ corresponds to N-H vibrations. The absorption band at $1623 \mathrm{~cm}^{-1}$ corresponds to $\mathrm{C}=\mathrm{N}$ vibrations and the one at $1357 \mathrm{~cm}^{-1}$ to vibrations of $\mathrm{C}-\mathrm{N}$ bonds. In the Se-init spectrum, one observes narrowing of absorption bands at 3311 and $3454 \mathrm{~cm}^{-1}$, which indicates the absence of expressed hydrogen bonds. The specific feature of the Se-init spectrum (Figure 1b) consists in the presence of peaks at 412 and $489 \mathrm{~cm}^{-1}$ corresponding to vibrations of Se-Se and $\mathrm{N}-\mathrm{Se}$ bonds, respectively. In addition, an important feature consists in the presence of the absorption bands at $1548 \mathrm{~cm}^{-1}$, corresponding to the $\mathrm{Se}=\mathrm{C}-\mathrm{N}$ bond vibrations, and $1105 \mathrm{~cm}^{-1}$, corresponding to the $\mathrm{C}-\mathrm{NO}$ bond vibrations.

The X-ray diffraction analysis showed the presence of peaks corresponding to the initial N'-hydroxy-1,2,5-oxadiazole-3-carboximidamide, which indicated the complete binding of the functional organic part with partial preservation of the original structure (27 ̊-Figure 2, X-ray Pattern b). The syngony and the spatial group P 3(1)21 were established-a structure similar to gray selenium ( $\beta$-Se) but different from it (Figure 2, $X$-ray pattern $b$ ). In addition, the Se-init $X$-ray pattern shows signals corresponding to the Se phases that were not earlier found in the published data.

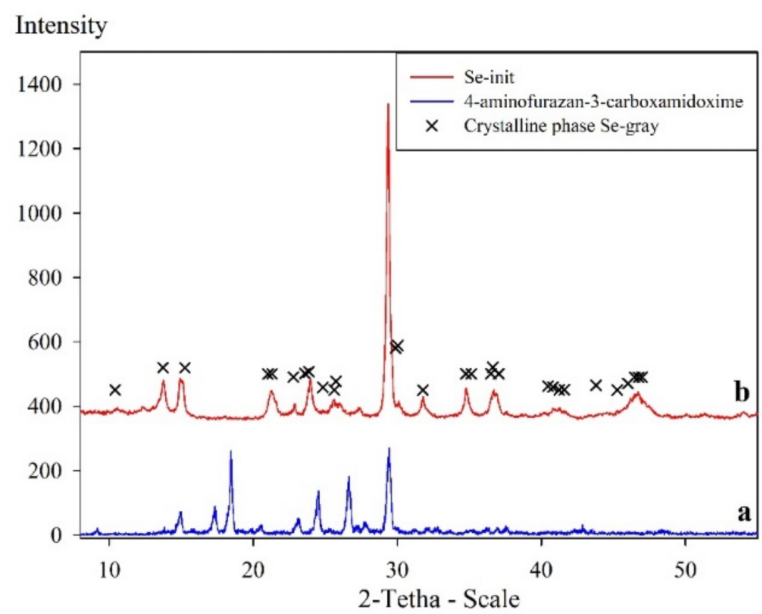

Figure 2. X-ray images of: (a) 4-aminofurazane-3-carboxamidoxime; (b) Se-init.

The presence of the crystal structure can be indirectly corroborated by the images of scanning electron microscopy (Figure 3). One can see that the morphology of the Se-init surface is represented by clearly expressed crystallites of irregular structures and sizes. 


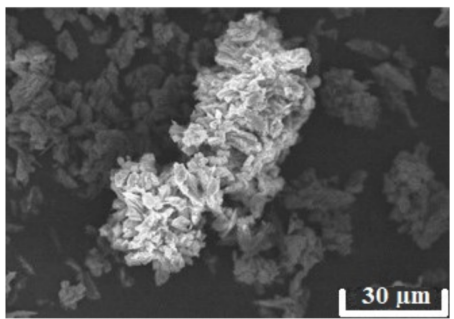

(a)

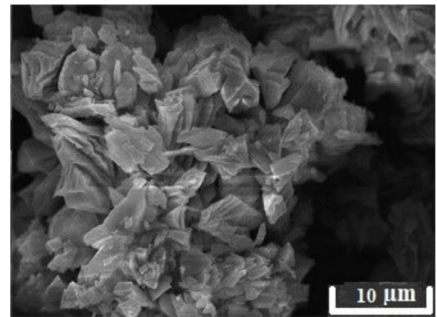

(b)

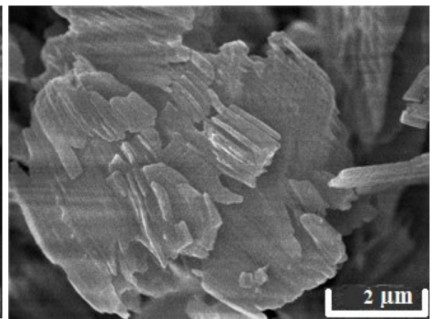

(c)

Figure 3. Se-init SEM images at different resolutions: (a) $\times 1500$; (b) $\times 2500$; (c) $\times 5000$.

The material was analyzed by the method of solid-state NMR on ${ }^{13} \mathrm{C}$ and ${ }^{1} \mathrm{H}$ nuclei. In the ${ }^{13} \mathrm{C}$ spectrum (Figure 4a), there is a clearly expressed signal at $138 \mathrm{ppm}$ corresponding to carbon at the oxime group $-\mathrm{C}=\mathrm{NOH}$, as well as signals of $146 \mathrm{ppm}$ corresponding to the $-\mathrm{HN}-\mathrm{C}=$ and $154 \mathrm{ppm}$ typical for $=\mathrm{C}-\mathrm{C}=($ Table 1$)$. In the PMR spectrum (Figure $4 \mathrm{~b}$ ), there are signals of $1.5 \mathrm{ppm}$ corresponding to the proton at aliphatic $\mathrm{C}-\mathrm{NH}$, and $7.1 \mathrm{ppm}$ corresponding to $\mathrm{H}-\mathrm{N}(\mathrm{C})-\mathrm{Se}$.

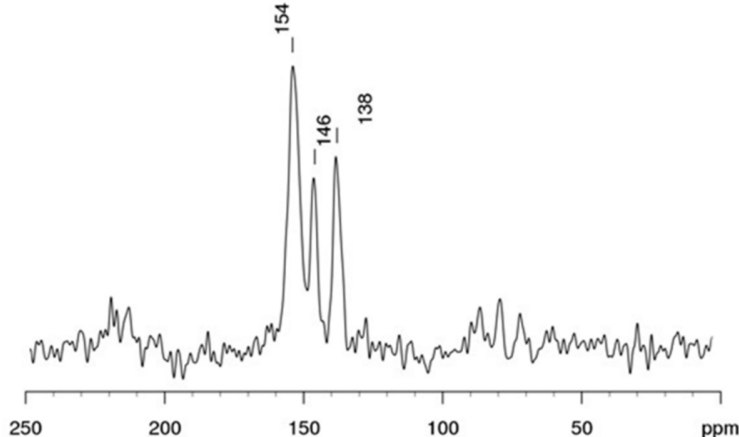

(a)

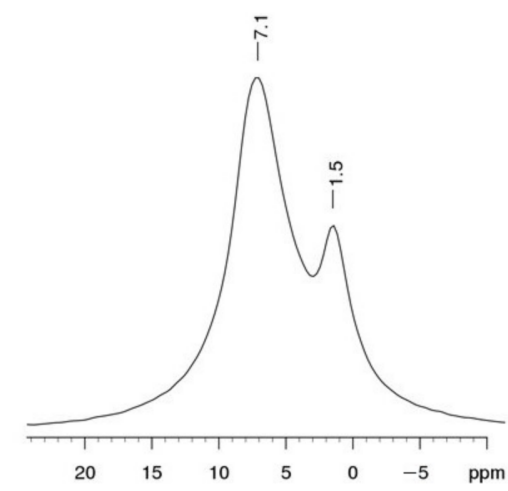

(b)

Figure 4. Se-init spectra: (a) ${ }^{13} \mathrm{C}$ NMR, (b) PMR.

Table 1. Se-init Surface Element Analysis.

\begin{tabular}{ccccc}
\hline Analysis Method & C, at. $\%$ & N, at.\% & O, at.\% & Se, at.\% \\
\hline Theoretical & 29.97 & 46.70 & 16.67 & 6.66 \\
EDS Analysis & 29.41 & 44.38 & 17.94 & 8.28 \\
XPS & 33.80 & 45.20 & 16.10 & 6.85 \\
REM & 31.88 & 43.97 & 17.05 & 6.50 \\
\hline
\end{tabular}

The additional PMR analysis in the liquid phase was performed: it showed the presence of an additional signal with an intensity of 3 at $2.73 \mathrm{ppm}$, which probably corresponded to three acetylene protons. Figure 5 shows the XPS spectra of the prepared material. In order to obtain a more accurate understanding of the structure of the compound, the material was pre-washed with distilled water and ethanol alcohol to remove the synthesis by-products.

The XPS spectrum shows the presence of a C 1s peak (Figure 5b) around $285.0 \mathrm{eV}$, which corresponds to the aliphatically bound carbon at the position $\mathrm{CH}_{2}-\mathrm{CH}-$; the peak of $286.9 \mathrm{eV}$ corresponds to the tri-substituted carbon $\mathrm{NH}_{2}-\mathrm{CH}=\mathrm{N}-\mathrm{OH}$. A signal of energy of $288.5 \mathrm{eV}$ corresponds to the groups $\mathrm{C}-\mathrm{N} / \mathrm{C}=\mathrm{N}$. In the region corresponding to $\mathrm{N} 1 \mathrm{~s}$ (Figure 5c), there are peaks with binding energies of $399.2 \mathrm{eV}$ typical for triazine-type nitrogen $\mathrm{C}-\mathrm{N}-\mathrm{OH}$ and of $400.4 \mathrm{eV}$ corresponding to thiadiazole-type nitrogen, probably bound to the selenium atom (Se-NH-C). The signals of the $\mathrm{O} 1$ s peak (Figure $5 \mathrm{~d}$ ) with binding energies of $533.6 \mathrm{eV}$ and $531.2 \mathrm{eV}$ correspond to an oxygen atom with surroundings 
of $\mathrm{NH}_{2}-\mathrm{C}=\mathrm{N}-\mathrm{O}-\mathrm{N}$ and $\mathrm{N}-\mathrm{O}-\mathrm{H}$, respectively. The position of the Se 3p peak (Figure 5e) of the binding energy of $164.0 \mathrm{eV}$ is typical for tetravalent selenium, probably bound to the second selenium atom by a double bond $(>\mathrm{Se}=\mathrm{Se}<)$. The spectrum also contains a signal at $169.3 \mathrm{eV}$ corresponding to a selenium atom with the $\mathrm{C}-\mathrm{NH}-\mathrm{Se}$ surrounding.

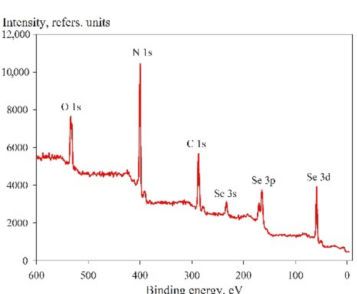

(a)

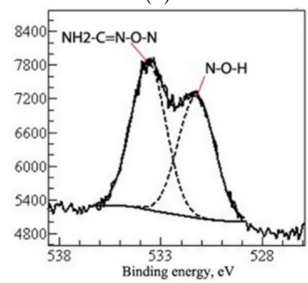

(d)

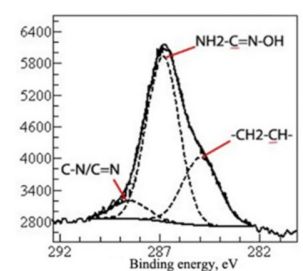

(b)

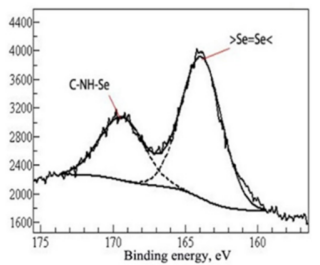

(e)

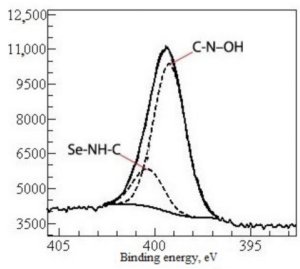

(c)

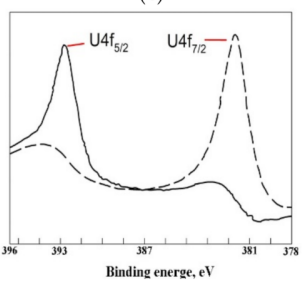

(f)

Figure 5. Se-init XPS spectra: (a) general view; (b) C 1s, (c) N 1s, (d) O 1s, (e) Se 3p, (f) U 4f.

Based on the performed physical and chemical analysis, we suggested the mechanism of binding of compound 1 (Figure 6) to selenium dioxide and suggested the molecular structure of the resulting material (Figure 6).

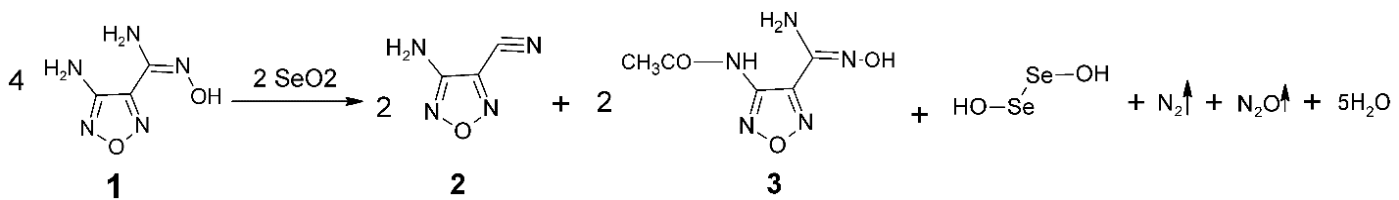

(a)

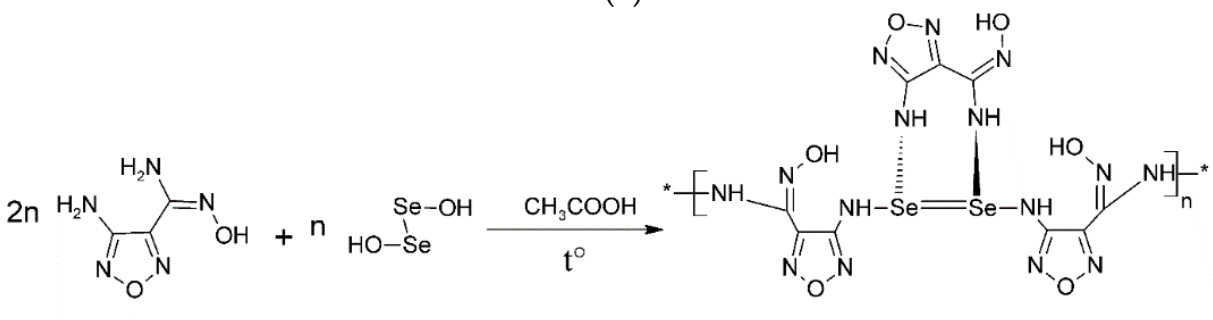

(b)

Figure 6. Mechanism for producing Se-init; (a) first stage; (b) second stage.

It was found that, as a result of the polycondensation reaction, the degree of oxidation of Se (IV) is preserved with the formation of a strong double bond $>\mathrm{Se}=\mathrm{Se}<$ bound by functional amidoxime radicals.

During the synthesis, compounds 2 and 3 remained in the dissolved phase and were then completely removed by repeated washing with distilled water and organic solvents, as evidenced by the results of the analysis of the material (Table 1).

Table 1 shows the data calculated for an elementary unit of Se-init (Figure 6). The experimental percent values of the elements match the theoretically calculated ones with insignificant deviations, which is probably related to the presence of non-removable monomeric or oligomeric structures. 


\subsection{Sorption Selective Properties}

Figure 7 shows the experimental results of the determination of the zero charge point $\left(\mathrm{pH}_{\mathrm{pzc}}\right)$ using a $\mathrm{NaNO}_{3}$ solution of a concentration of $0.01 \mathrm{~mol} \mathrm{~L}^{-1}$. The results are shown in the form of a dependence of the equilibrium $\mathrm{pH}$ of solutions after contact with a sorbent on the initial $\mathrm{pH}$ of these solutions. The bend point on curve 3 corresponds to the zero charge point that is the value of the solution $\mathrm{pH}$, at which the sorbent surface is uncharged. In our case, the $\mathrm{pH}_{\mathrm{pzc}}$ value is equal to 4.3. Below this value of solution $\mathrm{pH}$, the sorbent surface is charged positively, which prevents uranium adsorption due to electrostatic repulsion. Above $\mathrm{pH}_{\mathrm{pzc}}$, the sorbent surface is charged negatively, which positively affects the efficiency of recovery of uranium and its hydrated cationic forms.

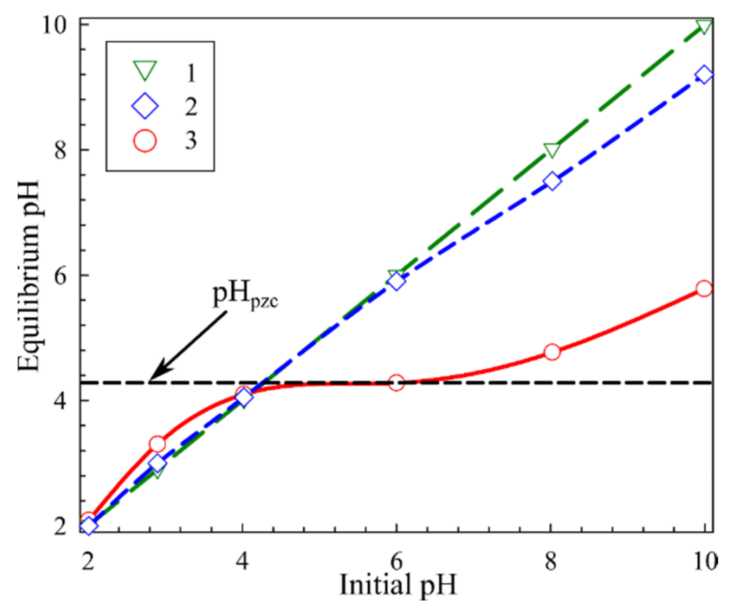

Figure 7. Point of zero charge $\left(\mathrm{pH}_{\mathrm{pzc}}\right)$ of the sorbent, 1-initial $\mathrm{pH}$ solution, 2-blank experiment ( $\mathrm{pH}$ changing without sorbent), 3-changing the $\mathrm{pH}$ solution after contact with sorbent, within $24 \mathrm{~h}$.

The results of the determination of $\mathrm{pH}_{\mathrm{pzc}}$ are in good agreement with the dependence of the efficiency of uranium recovery on the solution $\mathrm{pH}$ (Figure 8). The solution $\mathrm{pH}$ correction was carried out using solutions of $\mathrm{HNO}_{3}$ and $\mathrm{NaOH}$. In acidic solutions, low recovery efficiency is related to positively charged sorbent surface as, probably, to the predominant reaction of protonation.

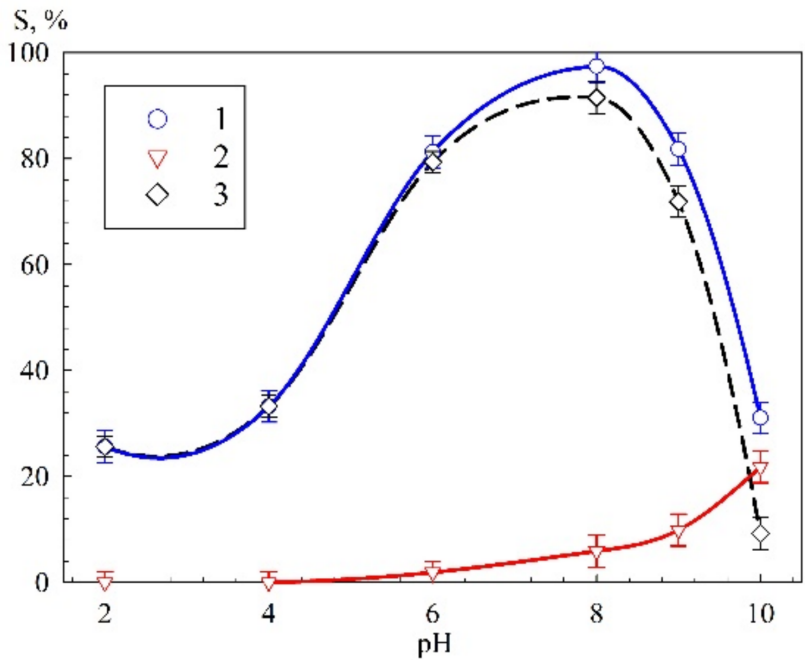

Figure 8. Dependence of the uranium sorption on $\mathrm{pH}$ of the model solution, 1-Se-init, 2-blank experiment, 3-adsorption efficiency taking into account adsorption on the flask walls.

The form of uranium presence in a solution depends significantly on the solution $\mathrm{pH}$. In solutions with $\mathrm{pH}$ above 4 , one observes the increase in the uranium recovery 
due to strong binding by the adsorbent negatively charged surface and predominant cationic hydrate forms of uranium. The dependence of the composition of the hydrated uranium cation with the $\mathrm{pH}$ increase (from 4 to 8 ) is expressed in the row $\mathrm{UO}_{2} \mathrm{OH}^{+} \rightarrow$ $\left(\mathrm{UO}_{2}\right)_{2}(\mathrm{OH})_{2}{ }^{2+} \rightarrow\left(\mathrm{UO}_{2}\right)_{3}(\mathrm{OH})^{5+}$ [37]. The recovery efficiency maximum is attained at $\mathrm{pH}$ 8 , with a subsequent decrease at the transition to the alkaline range. The decrease in the efficiency of uranium recovery in solutions with $\mathrm{pH}$ above 8 is probably related to the increased formation of the anionic form of uranium $\mathrm{UO}_{2}(\mathrm{OH})^{3-}$ [37] and the uranium adsorption on the flask walls, which was found in the control experiment without the sorbent (curve 3, Figure 8). The high efficiency of the uranium recovery is explained by the presence of a large number of sorption sites forming at polymer formation as a result of polycondensation of cyclic molecules through the $>\mathrm{Se}=\mathrm{Se}<$ bond.

Table 2 shows the values of the sorption-selective properties of the sorbent, depending on the initial $\mathrm{pH}$ of the solution. According to the obtained data, these materials can be recommended for the recovery of uranium from neutral and slightly alkaline solutions. A change in the value of $\mathrm{pH}$ of the model solution as compared to the initial value was observed. This was probably the result of deprotonation of the $=\mathrm{N}-\mathrm{O}-\mathrm{H}$ group during the adsorption.

Table 2. Dependence of the uranium ${ }^{+}$adsorption parameters on the $\mathrm{pH}$ of the medium.

\begin{tabular}{|c|c|c|}
\hline $\mathrm{pH}$ Initial & $K_{d} \times 10^{-3}, \mathrm{~cm}^{3} \mathrm{~g}^{-1}$ & SEC, $\mathrm{mg} \mathrm{g}^{-1}$ \\
\hline 2 & 0.3 & 3.0 \\
\hline 4 & 0.5 & 4.3 \\
\hline 6 & 5.0 & 9.7 \\
\hline 8 & 37.9 & 15.8 \\
\hline 9 & 4.2 & 9.1 \\
\hline 10 & 0.5 & 2.9 \\
\hline
\end{tabular}

Figure 9 shows a diagram of the dependence of the SEC uranium values on the concentration of cations in the solution. It was found that double-charged cations reduce the SEC value to a greater extent than single-charged cations, which is explained by the electrostatic interaction, as well as due to the larger number of occupied adsorption sites, which is associated with an increase in the equivalence factor of multiply charged elements. The sequence of cations by the degree of increasing negative impact on the value of SEC is as follows: $\mathrm{Na}^{+} \leq \mathrm{K}^{+}<\mathrm{Mg}^{2+} \leq \mathrm{Ni}^{2+} \leq \mathrm{Ca}^{2+} \leq \mathrm{Co}^{2+}$. However, it is worth mentioning that despite the decrease in SEC values at increasing the concentration of competing cations, the efficiency of the uranium recovery exceeds $75 \%$, regardless of the competing ions.

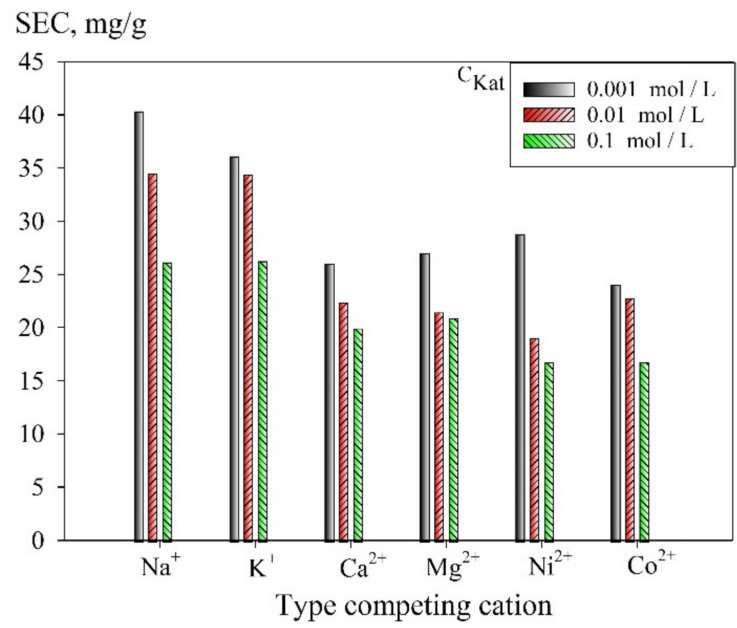

Figure 9. Diagram of the dependence of SEC (uranium) values on the type and amount of competing cations $\left(\mathrm{V} / \mathrm{m}=1000 \mathrm{~mL} \mathrm{~g}^{-1}, \mathrm{pH} 6\right)$, obtained at $25^{\circ} \mathrm{C}$. 
The uranium extraction efficiency in the presence of other (competing) cations at $\mathrm{pH} 6$ and 8 is generally comparable to each other. For this reason, this experiment was carried out only at pH6. The most negative effect on the uranium extraction efficiency is exerted by anions, the effect of which strongly depends on the solution $\mathrm{pH}$.

Uranium undergoes hydrolysis and has the affinity to complexation: this effect is clearly expressed in neutral and slightly alkaline media, which significantly complicates its recovery by sorption. The presence of various anions in the solutions, such as bicarbonates or sulfates, can significantly reduce the efficiency of uranium extraction. Experiments were carried out to estimate the negative effect of anions.

Figure 10 shows the curves of the dependence of the SEC uranium values on the type and concentration of some anions that may be present in natural and technological liquid media.

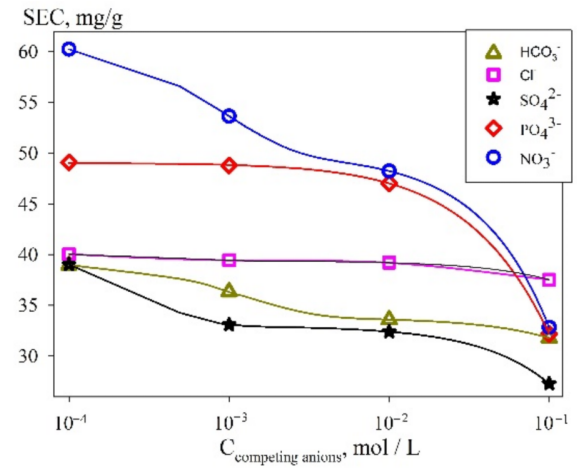

(a)

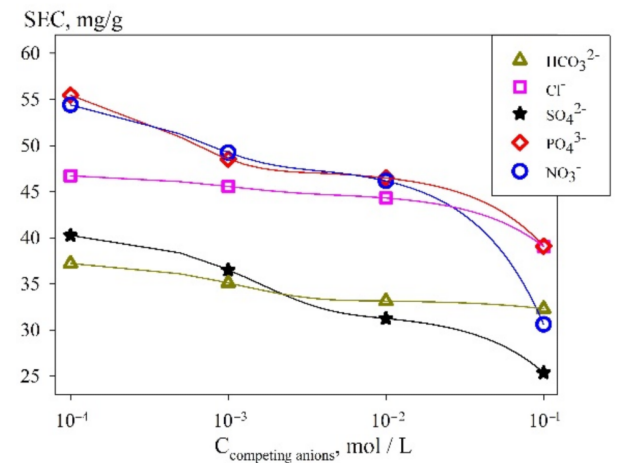

(b)

Figure 10. Dependence of SEC (uranium) values on the type and concentration of competing anions in a solution with (a) $\mathrm{pH} 6$; (b) $\mathrm{pH} 8$, obtained at $25^{\circ} \mathrm{C}$.

It was found that the anions negatively affected the SEC value to varying degrees. The sequence of anions according to the degree of increasing negative impact on the value of SEC is as follows: $\mathrm{NO}_{3}{ }^{-}<\mathrm{PO}_{4}{ }^{3-}<\mathrm{Cl}^{-}<\mathrm{HCO}_{3}{ }^{-}<\mathrm{SO}_{4}{ }^{2-}$. The greatest negative effect is provided by bicarbonate and sulfate ions, which is explained by the formation of stable anionic complexes of the type $\left[\mathrm{UO}_{2}\left(\mathrm{SO}_{4}\right)_{3}\right]^{4-},\left[\left(\mathrm{UO}_{2}\right)_{2} \mathrm{CO}_{3}(\mathrm{OH})_{3}\right]^{-},\left[\mathrm{UO}_{2}\left(\mathrm{CO}_{3}\right)_{3}\right]^{4-}$, $\left[\mathrm{UO}_{2}\left(\mathrm{CO}_{3}\right)_{2}\right]^{2-}$ and $\left[\mathrm{UO}_{2}\left(\mathrm{CO}_{3}\right)_{2}\left(\mathrm{H}_{2} \mathrm{O}\right)_{2}\right]^{2-}$ [38], the probability of their formation increases with the $\mathrm{pH}$ growing. However, when the anion concentration is equal to $0.01 \mathrm{~mol} \mathrm{~L}^{-1}$, one observes less than a two-fold decrease in the adsorption of uranium, which is also associated with the formation of complex ions such as $\left[\mathrm{UO}_{2} \mathrm{NO}_{3}\right]^{+},\left[\mathrm{UO}_{2} \mathrm{PO}_{4}\right]^{-},\left[\mathrm{UO}_{2} \mathrm{Cl}\right]^{+}$ $\mathrm{UO}_{2} \mathrm{Cl}_{2}{ }^{0}$, etc. [39]. The weakening of the sorption properties in alkaline solutions is related to the partial oxidation of the organic radical, accompanied by the destruction of the sorbent.

The Se-init after the sorption of uranyl ions was analyzed by the XPS spectroscopy: the results showed the presence of $U$ ff signals with binding energies of 392.8 and $382.0 \mathrm{eV}$, which indicated the binding of uranyl ions in the sorbent due to complexation and partial ion exchange. Figure 11 illustrates the structure of the binding of uranyl ions by Se-init. After the deprotonation reaction of the $-\mathrm{OH}$ group, the binding of the radionuclide can proceed according to the M1 mechanism in acidic or neutral media, as well as by the M2 mechanism (Figure 11) in slightly alkaline and alkaline media due to binding of the oxygen and nitrogen atoms at the oxime group.

The preservation of mechanical stability is an important requirement for sorption materials created for long-term use in sorption columns. This requirement can be fulfilled by developing composite materials by depositing them on a mechanically stable matrix. 


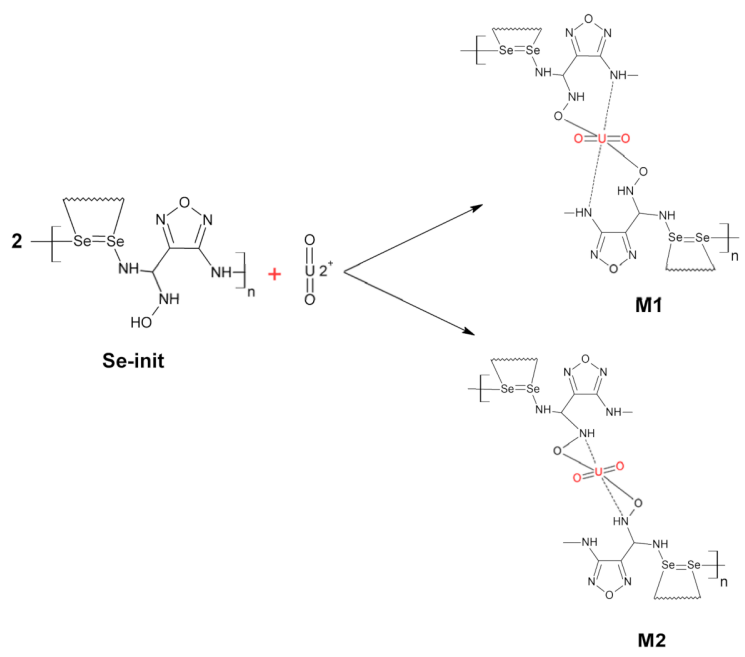

Figure 11. Scheme of possible structure of binding of uranium to Se-init.

In the present work, silica gel was used as such a matrix: it was modified with a polymer-based on the Se-derivative of amidoxime. Table 3 shows the surface characteristics of the resulting materials: the data were obtained using nitrogen adsorption and subsequent calculation according to the BET equation. It was shown that, unlike the initial material (Se-init), the composite materials have a more developed surface, which increases proportionally to the increase in the weight content of silica gel.

Table 3. Results of the study of the surface of materials by the method of nitrogen absorption.

\begin{tabular}{ccccc}
\hline Parameter & Si-Init & Se-35 & Se-50 & Se-65 \\
\hline Silica gel content, $\mathrm{wt}^{\circ} \%$ & 0 & 35 & 50 & 65 \\
Pore volume, $\mathrm{cm}^{3} \mathrm{~g}^{-1}$ & 0.05 & 0.45 & 0.51 & 0.65 \\
Specific surface area, $\mathrm{ml} \mathrm{g}^{-1}$ & 2 & 210 & 243 & 298 \\
Specific pore size, $\mathrm{nm}$ & 1.21 & 12.1 & 12.1 & 12.1 \\
\hline
\end{tabular}

Figure 12 shows the adsorption isotherms obtained in the solutions with $\mathrm{pH} 6$ (Figure 12a) and pH 8 (Figure 12b), which can be attributed to the L-type [40], thus indicating a high affinity of the adsorbents to uranium. Besides, the highest SEC is attained at $\mathrm{pH} 8$, which is probably related to peculiarities of the ionic form of uranium in solution: in particular, at $\mathrm{pH} 8$, the predominant forms are $\mathrm{UO}_{2}(\mathrm{OH})_{3}{ }^{-}$and $(\mathrm{UO} 2)_{3}(\mathrm{OH})_{5}{ }^{+}$, while at $\mathrm{pH}$ 6 - $\mathrm{UO}_{2}(\mathrm{OH})^{+},\left(\mathrm{UO}_{2}\right)_{2}(\mathrm{OH})_{2}{ }^{2+}, \mathrm{UO}_{2}(\mathrm{OH})_{2}{ }^{0}$, and $(\mathrm{UO} 2)_{3}(\mathrm{OH})_{5}{ }^{+}$, respectively [37].

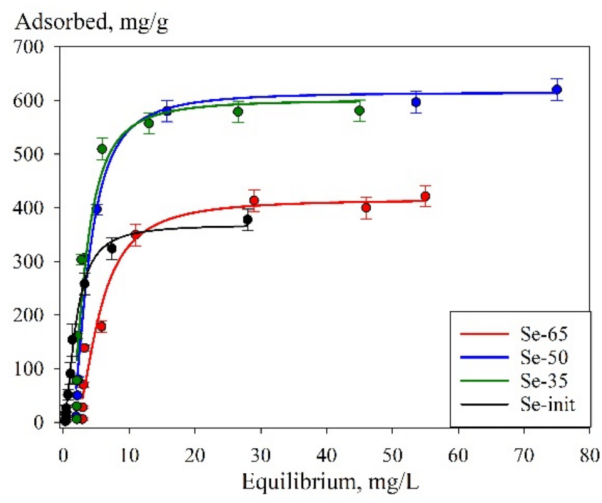

(a)

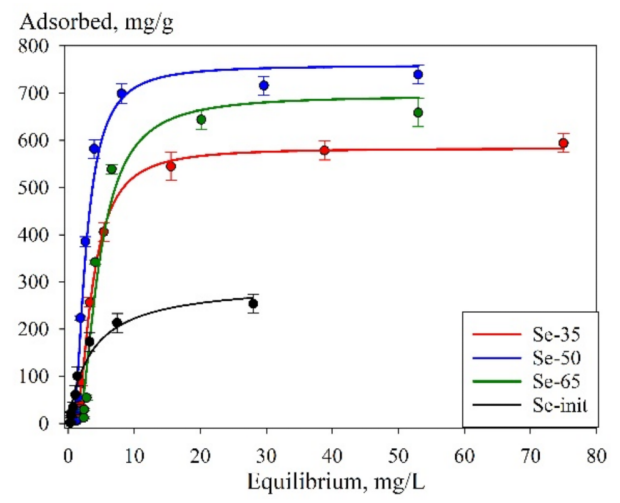

(b)

Figure 12. Sorption isotherms of uranium $((\mathbf{a})-\mathrm{pH} 6,(\mathbf{b})-\mathrm{pH} 8)$ and approximation of the experimental values by the Langmuir equation, obtained at $25^{\circ} \mathrm{C}$. 
Table 4 shows the values of $G_{\max }$ and the adsorption equilibrium constant $K_{l}$ obtained by approximating the experimental points. The coefficient of determination exceeds 0.95 , which indicates that the chosen model is correct. For the composite sorbents, the values of the adsorption equilibrium constant are quite close, which indicates the preservation of the adsorption mechanism. The adsorption equilibrium constants obtained for the composites have lower values in comparison with Se-init due to the reduced content of the sorption-active component (Se-derivative of 4-aminofurazane-3-carboxamidoxime). The highest values of the maximum adsorption were obtained for Se-50 and Se-65, which could be related to the greater availability of adsorption sites; however, we do not exclude the adsorption of uranyl ions on silica gel.

Table 4. Constants of the Langmuir equation calculated after approximating the experimental data.

\begin{tabular}{cccccc}
\hline & Parameter & Se-Init & Se-35 & Se-50 & Se-65 \\
\hline & $\mathrm{G}_{\max }$ & $370 \pm 20$ & $420 \pm 20$ & $620 \pm 20$ & $600 \pm 30$ \\
$\mathrm{pH}-6$ & $\mathrm{~K}_{1}$ & $0.24 \pm 0.05$ & $0.14 \pm 0.07$ & $0.14 \pm 0.05$ & $0.14 \pm 0.07$ \\
& $\mathrm{R}^{2}$ & 0.98 & 0.96 & 0.98 & 0.94 \\
$\mathrm{pH}-8$ & $\mathrm{G}_{\max }$ & $270 \pm 10$ & $580 \pm 20$ & $760 \pm 30$ & $690 \pm 20$ \\
& $\mathrm{~K}_{1}$ & $0.30 \pm 0.07$ & $0.19 \pm 0.05$ & $0.18 \pm 0.07$ & $0.21 \pm 0.09$ \\
& $\mathrm{R}^{2}$ & 0.98 & 0.99 & 0.97 & 0.98 \\
\hline
\end{tabular}

The highest values of the maximum adsorption were obtained for Se-50 and Se65 , which could be related to the greater availability of adsorption sites and also with partial adsorption of uranium on silica gel. In order to evaluate the silica gel effect on the composite's sorption characteristics, a control experiment was carried out. In the control experiment, the efficiency of uranium adsorption with unmodified silica gel was evaluated.

Figure 13 shows the diagram of uranium sorption from model solutions with pH 6 and 8 on synthesized materials and pure silica gel used in the fabrication of composite materials. It is known that various types of silica gels are capable of adsorbing heavy metal ions from liquid media [41,42]. It should be noted that unmodified silica gel cannot efficiently extract uranium since ion-exchange hydroxyl groups in silica gel do not exhibit high selectivity to uranium in the presence of other metal ions and anions. In addition, the binding of uranium by embedding it in the crystal lattice of silica gel is significantly limited due to the low sorption capacity of the synthetic mineral. The efficiency of uranium extraction from the model solution does not exceed 50\%; therefore, unmodified silica gel is not an effective sorbent. However, its use as a matrix for composite materials (along with Se-init) promotes the improvement of sorption properties, which is reflected in the increase in the efficiency of recovery (Figure 13) and SEC (Table 4), relatively to Se-init.

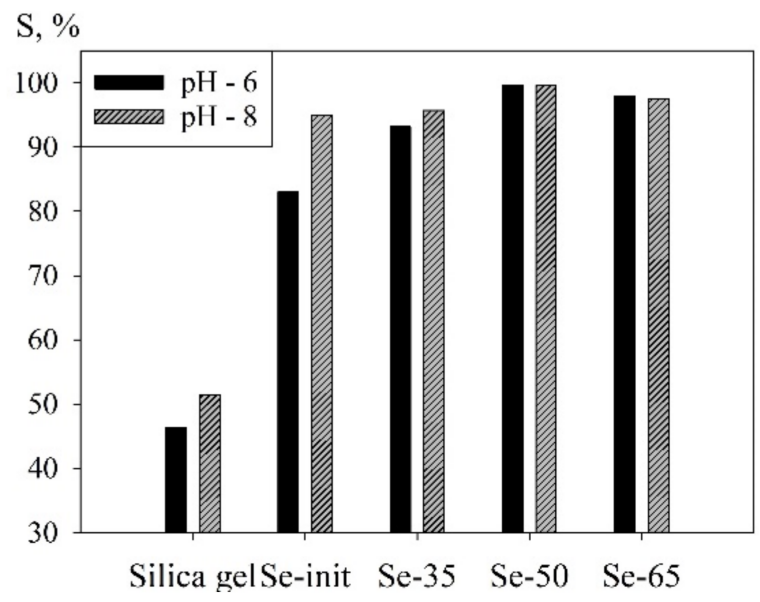

Figure 13. Sorption of uranium from model solutions, $\mathrm{a}-\mathrm{pH} \mathrm{6,} \mathrm{b}-\mathrm{pH} 8$, using various materials. 
We evaluated the kinetic characteristics of the adsorption process on the composite sorbents. Figure 14 shows the kinetic curves of the sorption of uranium from the model solution in semi-logarithmic coordinates (Figure 14a). The kinetic curves indicate that the adsorption process on the composite sorbents proceeds at a higher rate, which is also associated with greater availability of the adsorption sites as compared with the noncomposite sorbent. An increase in the specific surface area of composite materials leads to a decrease in the time to reach equilibrium adsorption, which is 10-20 $\mathrm{min}$, while the adsorption efficiency exceeds $95 \%$. A significant increase in the time to reach adsorption equilibrium on the Se-init sample is probably associated with the specific features of the adsorption process in the presence of uranium in various ionic forms. In addition, the diffusion process is important in the uranium-binding rate on a dense surface of a non-porous material, which in this case is likely to be limiting.

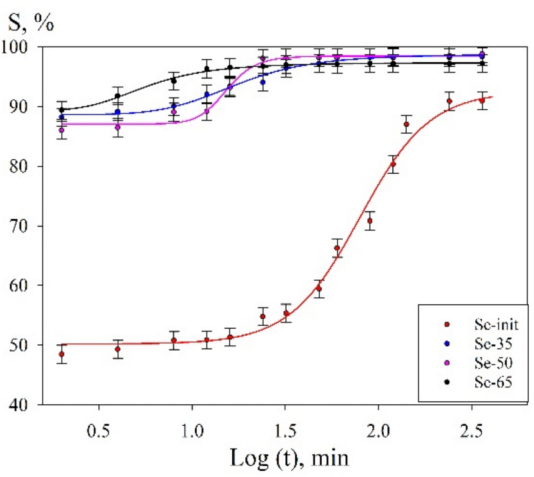

(a)

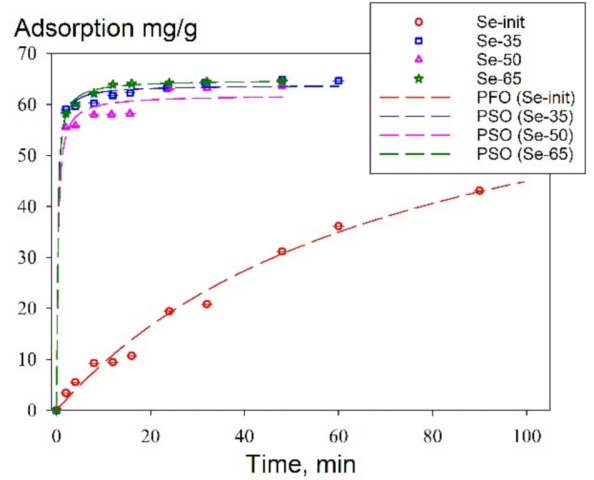

(b)

Figure 14. The recovery of uranium from the model solution under static conditions at $25^{\circ} \mathrm{C}(\mathrm{V} / \mathrm{m}$ $\left.=200 \mathrm{~mL} \mathrm{~g}^{-1}\right) ;(\mathbf{a})$ — kinetic curves in semi-logarithmic coordinates; (b)—curves of the adsorption dependence $\left(\mathrm{mmol} \mathrm{g}^{-1}\right)$ on time.

Figure 15 shows high-resolution SEM images for Se-init and the composite sorbents. Unlike Se-init, whose structure is represented by pronounced crystallites, the surface of the composite sorbents is relatively homogeneous and contains small particles of presumably the sorption-active component. The surface distribution of the sorption-active component indirectly corroborates the fact that the adsorption sites of the composite sorbent can have greater accessibility in comparison with the Se-init material, some of the sorption sites of which are located in the bulk of dense crystallites and therefore do not participate in the exchange.

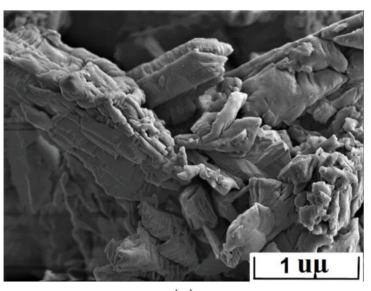

(a)

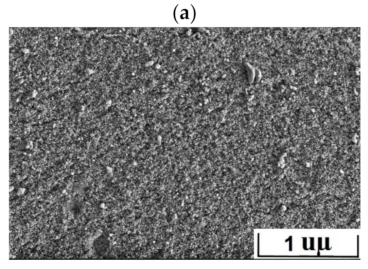

(c)

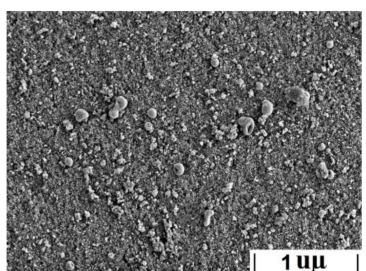

(b)

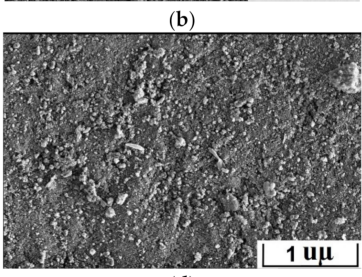

Figure 15. SEM images of the surface: (a) Se-init; (b) Se-35; (c) Se-50; (d) Se-65.

Table 5 shows the parameters calculated for the pseudo-first and pseudo-second order equations (Figure 14b). According to the determination coefficients, the kinetic adsorption 
curve of uranium for Se-init is better described by the pseudo-first-order equation, as opposed to the composite adsorbents. The increase in the reaction order for the composite sorbents could also indicate the increase in the availability of the adsorption sites and the predominance of the chemisorption process of uranium binding in comparison with the non-composite sorbent. It is also worth mentioning that the pseudo-second-order equation constant $k_{2}$ differs for different composite sorbents. For the sorbent Se-65, the calculated $k_{2}$ has the lowest value, which is associated with a reduced content of the sorption-active component affecting the kinetic characteristics.

Table 5. Calculated parameters for the pseudo-first and pseudo-second order equations.

\begin{tabular}{|c|c|c|c|c|c|}
\hline & $\begin{array}{c}\text { Equation } \\
\text { Type }\end{array}$ & $\mathbf{R}^{2}$ & $\mathrm{~A}, \mathrm{mg} \mathrm{g}^{-1}$ & $\mathbf{k}_{1}, \min ^{-1}$ & $\begin{array}{c}\mathrm{k}_{2,} \mathrm{mg} \mathrm{g}^{-1} \\
\min ^{-1}\end{array}$ \\
\hline Se-init & \multirow{4}{*}{$\mathrm{PFO}$} & 0.999 & $54.7 \pm 5.5$ & $\begin{array}{c}0.003 \pm \\
0.0002\end{array}$ & - \\
\hline Se-35 & & 0.932 & $62.2 \pm 3.7$ & $0.015 \pm 0.003$ & - \\
\hline Se-50 & & 0.953 & $60.1 \pm 4.7$ & $0.010 \pm 0.002$ & - \\
\hline Se-65 & & 0.931 & $62.7 \pm 3.8$ & $0.012 \pm 0.002$ & - \\
\hline Se-init & \multirow{4}{*}{ PSO } & 0.853 & $28.9 \pm 7.7$ & - & $0.80 \pm 0.04$ \\
\hline Se-35 & & 0.998 & $62.2 \pm 1.5$ & - & $9.50 \pm 0.80$ \\
\hline Se-50 & & 0.999 & $62.4 \pm 2.4$ & - & $7.80 \pm 0.60$ \\
\hline Se-65 & & 0.998 & $64.8 \pm 2.5$ & - & $6.60 \pm 0.50$ \\
\hline
\end{tabular}

Table 6 shows the results of testing the hydro-mechanical strength of the fabricated materials. One can note that at a transfer to Se-35, the material loses stability rather sharply, which is probably related to an excess of the sorption-active component washed off from the surface of the matrix during the stirring. The latter is corroborated by the fact that Se-init is mostly peptized in the model solutions, which complicates working with it.

Table 6. Degree of mechanical destruction of the materials.

\begin{tabular}{ccccc}
\hline Material & Se-init & Se-35 & Se-50 & Se-65 \\
\hline $\begin{array}{c}\text { Degree of } \\
\text { destruction\% }\end{array}$ & 8.1 & 5.2 & 0.8 & 0.6 \\
\hline
\end{tabular}

\section{Conclusions}

To sum up, a new approach to the synthesis of sorption materials containing amidoxime functional groups in their structure was developed. In particular, the Se-derivative 4-aminofurazane-3-carboxamidoxime was synthesized by polycondensation of individual substances in the presence of polar organic solvents. The molecular structure of the elementary unit of the initial Se-derived amidoxime was established, which indicates the formation of strong bridging bonds: $>\mathrm{Se}=\mathrm{Se}<$.

The sorption properties of the material under static conditions in the presence of both various cations and anions were characterized. The materials manifest mechanical and chemical stability, as well as high sorption-selective characteristics towards uranium in the $\mathrm{pH}$ range of 6-9.

In order to increase the kinetic parameters of ion exchange, the composite materials were fabricated based on the initial Se-derivative of amidoxime using silica gel as a matrix. The values of the maximum static exchange capacity in neutral and slightly alkaline model solutions were established: they equaled to $370 \mathrm{mg} \mathrm{g}^{-1}$ (pH-6) and $270 \mathrm{mg} \mathrm{g}^{-1}$ (pH-8) for Se-init and to $620 \mathrm{mg} \mathrm{g}^{-1}(\mathrm{pH}-6)$ and $760 \mathrm{mg} \mathrm{g}^{-1}$ (pH-8) for Se-50.

It was found that, along with the increase in the specific surface area of sorbents, the kinetic parameters of the uranium sorption increase by order of magnitude as compared to the non-porous material. 
Thus, the fabricated materials can be recommended for application in the recovery and concentration of uranium from technological and natural slightly alkaline waters with high mineralization.

Author Contributions: Conceptualization, A.E. and E.T.; formal analysis, A.E. and E.T.; funding acquisition, E.T.; investigation, E.T. and K.M.; methodology, K.M., E.T. and I.T.; writing—original draft, E.T.; writing — review and editing, A.E., E.T. and I.T. All authors have read and agreed to the published version of the manuscript.

Funding: The work was financially supported by the Russian Foundation for Basic Research (RFBR) (Project No. 19-33-90148). In addition, the study of sorption characteristics was carried out was partially supported within the frames of the State Order of the Institute of Chemistry of the Far Eastern Branch of the Russian Academy of Sciences (Project No. 0205-2021-0002).

Institutional Review Board Statement: Not applicable.

Informed Consent Statement: Not applicable.

Data Availability Statement: Data available on request due to restrictions eg privacy or ethical.

Acknowledgments: The equipment of CUC “Far Eastern Center of Structural Investigations" was used in this work.

Conflicts of Interest: The authors declare no conflict of interest.

\section{References}

1. Schnug, E.; Lottermoser, B.G. Fertilizer-Derived Uranium and Its Threat to Human Health. Environ. Sci. Technol. 2013, 47, 2433-2434. [CrossRef]

2. Beltrami, D.; Cote, G.; Mokhtari, H.; Courtaud, B.; Moyer, B.A.; Chagnes, A. Recovery of Uranium from Wet Phosphoric Acid by Solvent Extraction Processes. Chem. Rev. 2014, 114, 12002-12023. [CrossRef]

3. Shen, J.; Schäfer, A. Removal of Fluoride and Uranium by Nanofiltration and Reverse Osmosis: A Review. Chemosphere 2014, 117, 679-691. [CrossRef]

4. Chen, K.; Chen, C.; Ren, X.; Alsaedi, A.; Hayat, T. Interaction Mechanism between Different Facet $\mathrm{TiO}_{2}$ and U(VI): Experimental and Density-Functional Theory Investigation. Chem. Eng. J. 2019, 359, 944-954. [CrossRef]

5. Singh, D.K.; Hareendran, K.N.; Sreenivas, T.; Kain, V.; Dey, G.K. Development of a Phosphate Precipitation Method for the Recovery of Uranium from Lean Tenor Alkaline Leach Liquor. Hydrometallurgy 2017, 171, 228-235. [CrossRef]

6. Li, P.; Zhun, B.; Wang, X.; Liao, P.; Wang, G.; Wang, L.; Guo, Y.; Zhang, W. Highly Efficient Interception and Precipitation of Uranium(VI) from Aqueous Solution by Iron-Electrocoagulation Combined with Cooperative Chelation by Organic Ligands. Environ. Sci. Technol. 2017, 51, 14368-14378. [CrossRef]

7. Bhalara, P.D.; Punetha, D.; Balasubramanian, K. A Review of Potential Remediation Techniques for Uranium(VI) Ion Retrieval from Contaminated Aqueous Environment. J. Environ. Chem. Eng. 2014, 2, 1621-1634. [CrossRef]

8. Pauling, L. The Structure of the Chlorites. Proc. Natl. Acad. Sci. USA 1930, 16, 578-582. [CrossRef] [PubMed]

9. Fernandes, M.M.; Baeyens, B.; Dähn, R.; Scheinost, A.C.; Bradbury, M.H. U(VI) Sorption on Montmorillonite in the Absence and Presence of Carbonate: A Macroscopic and Microscopic Study. Geochim. Cosmochim. Acta 2012, 93, 262-277. [CrossRef]

10. Psareva, T.S.; Zakutevsk, O.I.; Strelko, V.V. Sorption of Uranium by Titanosilicate Ion Exchanger. Rep. NAS Ukr. 2003, 130-135. (In Russian)

11. Lv, Z.; Wang, H.; Chen, C.; Yang, S.; Chen, L.; Alsaedi, A.; Hayat, T. Enhanced Removal of Uranium(VI) from Aqueous Solution by a Novel Mg-MOF-74-Derived Porous MgO/Carbon Adsorbent. J. Colloid Interface Sci. 2019, 537, A1-A10. [CrossRef] [PubMed]

12. Ren, Y.; Bao, H.; Wu, Q.; Wang, H.; Gai, T.; Shao, L.; Wang, S.; Tang, H.; Li, Y.; Wang, X. The Physical Chemistry of Uranium (VI) Immobilization on Manganese Oxides. J. Hazard. Mater. 2020, 391, 122207. [CrossRef] [PubMed]

13. Papynov, E.K.; Tkachenko, I.A.; Maiorov, V.Y.; Pechnikov, V.S.; Fedorets, A.N.; Portnyagin, A.S.; Dran’kov, A.N.; Buravlev, I.Y.; Grishin, A.V.; Tananaev, I.G.; et al. Nanostructured Magnetic Sorbents for Selective Recovery of Uranium(VI) from Aqueous Solutions. Radiochemistry 2019, 61, 28-36. [CrossRef]

14. Amesh, P.; Suneesh, A.S.; Selvan, B.R.; Venkatesan, K.A.; Chandra, M. Magnetic Assisted Separation of Uranium(VI) from Aqueous Phase Using Diethylenetriamine Modified High Capacity Iron Oxide Adsorbent. J. Environ. Chem. Eng. 2020, 8, 103661. [CrossRef]

15. Pshinko, G.N. Impact of Humic Matter on Sorption of Radionuclides by Montmorrilonite. J. Water Chem. Technol. 2009, 31, 163-171. [CrossRef]

16. Zheleznov, V.V.; Maiorov, V.Y.; Polyakova, N.V.; Silant'ev, V.E.; Sokol'nitskaya, T.A.; Sushkov, Y.V.; Voit, E.I. Sorption of U(VI) onto $\mathrm{TiO} 2 / \mathrm{ZrO} 2 / \mathrm{SiO} 2$ Mesoporous Materials from Sulfate Solutions. Radiochemistry 2018, 60, 618-624. [CrossRef] 
17. Müller, K.; Foerstendorf, H.; Brendler, V.; Rossberg, A.; Stolze, K.; Gröschel, A. The Surface Reactions of U(VI) on $\gamma$-Al2O3-In Situ Spectroscopic Evaluation of the Transition from Sorption Complexation to Surface Precipitation. Chem. Geol. 2013, 357, 75-84. [CrossRef]

18. Latham, A.H.; Williams, M.E. Controlling Transport and Chemical Functionality of Magnetic Nanoparticles. Acc. Chem. Res. 2008, 41, 411-420. [CrossRef]

19. Strelko, V.V.; Psareva, T.S.; Zakutevskij, O.I.; Kanibolotskij, V.A.; Meleshevich, S.I. Sorption of U by titanosilicate ionites. Dopov. Natsyional'noyi Akad. Nauk Ukrayini 2005, 37, 142-147. (In Russian)

20. Kosyakov, V.N.; Veleshko, I.E.; Yakovlev, N.G.; Gorovoi, L.F. Preparation, Properties, and Application of Modified Mikoton Sorbents. Radiochemistry 2004, 46, 385-390. [CrossRef]

21. Veleshko, I.E.; Veleshko, A.N.; Rumyantseva, E.V. Chitin and Chitosan Based Materials from Different Sources for Radionuclides Adsorption. Prikladnaya Fizika i Matematika 2015, 3, 12-18. (In Russian)

22. Szlachta, M.; Neitola, R.; Peräniemi, S.; Vepsäläinen, J. Effective Separation of Uranium from Mine Process Effluents Using Chitosan as a Recyclable Natural Adsorbent. Sep. Purif. Technol. 2020, 253, 117493. [CrossRef]

23. Kumar, G.P.; Kumar, P.A.; Chakraborty, S.; Ray, M. Uptake and Desorption of Copper Ion Using Functionalized Polymer Coated Silica Gel in Aqueous Environment. Sep. Purif. Technol. 2007, 57, 47-56. [CrossRef]

24. Sun, S.; Wang, A. Adsorption Properties of Carboxymethyl-Chitosan and Cross-Linked Carboxymethyl-Chitosan Resin with $\mathrm{Cu}(\mathrm{II})$ as Template. Sep. Purif. Technol. 2006, 49, 197-204. [CrossRef]

25. Gao, B.; Gao, Y.; Li, Y. Preparation and Chelation Adsorption Property of Composite Chelating Material Poly $\left(\mathrm{Amidoxime} / \mathrm{SiO}_{2}\right.$ towards Heavy Metal Ions. Chem. Eng. J. 2010, 158, 542-549. [CrossRef]

26. Zhao, Y.; Li, J.; Zhao, L.; Zhang, S.; Huang, Y.; Wu, X.; Wang, X. Synthesis of Amidoxime-Functionalized $\mathrm{Fe}_{3} \mathrm{O}_{4} @ S i \mathrm{O}_{2} \mathrm{Core}_{-} \mathrm{Shell}$ Magnetic Microspheres for Highly Efficient Sorption of U(VI). Chem. Eng. J. 2014, 235, 275-283. [CrossRef]

27. Hirotsu, T.; Katoh, S.; Sugasaka, K.; Sen, M.; Itagaki, T. Binding Properties of a Polymer Having Amidoxime Groups with Proton and Metal Ions. Sep. Sci. Technol. 1986, 21, 1101-1110. [CrossRef]

28. Yu, S.; Wang, X.; Tan, X.; Wang, X. Sorption of Radionuclides from Aqueous Systems onto Graphene Oxide-Based Materials: A Review. Inorg. Chem. Front. 2015, 2, 593-612. [CrossRef]

29. Das, S.; Oyola, Y.; Mayes, R.T.; Janke, C.J.; Kuo, L.-J.; Gill, G.; Wood, J.R.; Dai, S. Extracting Uranium from Seawater: Promising AF Series Adsorbents. Ind. Eng. Chem. Res. 2016, 55, 4110-4117. [CrossRef]

30. Antonik, L.M.; Khabibulina, A.G. Polyoximes: Synthesis, Structure, and Properties. Polym. Sci. Ser. C 2004, 46, 37-48. (In Russian)

31. Al-Harahsheh, M.; AlJarrah, M.; Mayyas, M.; Alrebaki, M. High-Stability Polyamine/Amide-Functionalized Magnetic Nanoparticles for Enhanced Extraction of Uranium from Aqueous Solutions. J. Taiwan Inst. Chem. Eng. 2018, 86, 148-157. [CrossRef]

32. Li, B.; Sun, Q.; Zhang, Y.; Abney, C.W.; Aguila, B.; Lin, W.; Ma, S. Functionalized Porous Aromatic Framework for Efficient Uranium Adsorption from Aqueous Solutions. ACS Appl. Mater. Interfaces 2017, 9, 12511-12517. [CrossRef] [PubMed]

33. Lindner, H.; Schneider, E. Review of Cost Estimates for Uranium Recovery from Seawater. Energy Econ. 2015, 49, 9-22. [CrossRef]

34. Stepanov, A. The usage OF AMIDOXOME of 4-amonofurazan -3-carboxylic acid in the synthesis of heterocyclic compound S (review). Bull. St PbSIT(TU) 2014, 51, 32-46. [CrossRef]

35. Tokar, E.A.; Maslov, K.V.; Egorin, A.M. Selenium-Derivative of N-Hydroxyamidine Aminofurazan for Extraction of Uranium from Liquid Media Patent RU 2741909C1. Priority to RU2020128578A 2021. Available online: https://patents.google.com/ patent/RU2741909C1/en?oq=Selenium-derivative+of +N-hydroxyamidine+aminofurazan +for+extraction+of + uranium + from + liquid+media+Patent+RU+2741909+C1 (accessed on 25 August 2021).

36. Busev, A.I.; Tiptsova, V.G.; Ivanov, V.M. Guide to the Analytical Chemistry of Rare Elements.-Rec. and Add. M Chem. 1978, 2432. (In Russian)

37. Putilina, V.S.; Galitskaia, I.V.; Iuganova, T.I. Sorbtsionnye Protsessy pri Zagriaznenii Podzemnykh vod TiAZhelymi Metallami i Radioaktivnymi Ėlementami; URAN: Analiticheskiı̌ obzor; Ékologiia; GPNTB SO RAN: Novosibirsk, Russia, 2014; ISBN 9785945602533.

38. Bogolepov, A.A.; Pshinko, G.N.; Kornilovich, B.Y. The Impact of Complexing Agents on the Processes of Sorption Treatment of Waters Containing Uranium. J. Water Chem. Technol. 2007, 29, 9-14. [CrossRef]

39. Uranium Geochemistry and Kd Values//Understanding Variation in Partition Coefficient, Kd. Values. In Geochemistry and Available Kd Values for Selected Inorganic Contaminants; Chapter 5; EPA 402-R-99-004B; US EPA, US DOE: Washington, DC, USA, 1999; Volume 2, pp. 5.65-5.77. Available online: http:/ / www.epa.gov/radiation/docs/kdreport/vol2/402-r-99-004b_ch5b.pdf (accessed on 20 August 1999).

40. Giles, C.H.; Smith, D.; Huitson, A. A General Treatment and Classification of the Solute Adsorption Isotherm. I. Theoretical. J. Colloid Interface Sci. 1974, 47, 755-765. [CrossRef]

41. Da'na, E. Adsorption of Heavy Metals on Functionalized-Mesoporous Silica: A Review. Microporous Mesoporous Mater. 2017, 247, 145-157. [CrossRef]

42. Sandoval, O.G.M.; Trujillo, G.C.D.; Orozco, A.E.L. Amorphous Silica Waste from a Geothermal Central as an Adsorption Agent of Heavy Metal Ions for the Regeneration of Industrial Pre-Treated Wastewater. Water Resour. Ind. 2018, 20, 15-22. [CrossRef] 